\title{
Management of Laryngotracheal Stenosis: A 10-Year Study on the Role of Stents
}

\author{
Ravikumar Arunachalam ${ }^{1}$ Saravanam Prasanna Kumar ${ }^{1}$
}

Address for correspondence Ravikumar Arunachalam, FAMS, Department of ENT, Head \& Neck Surgery, Sri Ramachandra Institute of Higher Education and Research, Porur, Chennai 600116, Tamil Nadu, India (e-mail: deaneducation@sriramachandra.edu.in).

\author{
Abstract \\ Keywords \\ - laryngotracheal \\ stenosis \\ - upper tracheal \\ dimensions \\ - postextubation laryn- \\ gotracheal injury \\ - Montgomery T-tube \\ laryngotracheal stents \\ - Shiann Yann Lee \\ tracheoplasty \\ - cricotracheal resection \\ and anastomosis
}

Introduction Laryngotracheal stenosis (LTS) is mostly due to road traffic accidents, prolonged intubation, and tracheostomy.

Objectives This study focused on a 10-year experience on the role of stents in the management of LTS in a tertiary referral hospital. The aims of this study were to study the internal dimensions of the subglottis and upper trachea in the Indian adult population; to study the mucosal response to injury to the subglottis and the trachea; and to develop an ideal stent for use in LTS in a rabbit model.

Materials and Methods The authors have been treating patients with LTS since 2000 . The present study deals with the experience of 82 cases of LTS treated over the past 10 years using stents as well as surgical procedures such as Shiann Yann Lee tracheoplasty and tracheal resection and anastomosis. The work also involved a focused research on LTS using rabbits by inducing injury to the mucosa of the upper trachea and subglottis and histological study of the response to injury. The study led to the development of new indigenous stent for use in rabbits to prevent LTS. This stent has been patented.

Statistical Analysis The study of the subglottis and upper tracheal discussion have been analyzed and proved that the dimension in the Indian adult population was smaller than in Caucasians. The mucosal inflammation following injury at the subglottis and upper trachea can be reversed by topical application of triamcinolone, which was better than Mitomycin on statistical analysis.

Results The quality of life measured after treatment of LTS using stents and other methods of reconstructive surgery has given an overall benefit of $90 \%$ with no mortality.

Conclusion LTS is a preventable disease. It can be prevented by proper care of patients in ICU and correct technique of endotracheal intubation and tracheostomy. Further, it can be avoided using medications during extubation and proper decannulation protocol. The silastic "T" tube stents are useful to improve the quality of life in these patients.

\section{Introduction}

Laryngotracheal stenosis (LTS) may be caused by trauma or by a benign or malignant lesion causing narrowing of the airway. Benign stenosis is mostly iatrogenic (prolonged endotracheal intubation, tracheostomy, etc.). Several modalities of management of LTS have been described in the literature. This in itself bears testimony to the complexity of the problem and the difficulty in restoring a normal airway. No single approach gives predictably satisfactory results. The surgical treatment has to be individualized for each patient. At present, the optimal treatment in severe LTS ${ }^{1}$ and procedure of choice ${ }^{2}$ is resection anastomosis. However, less severe degree of stenosis and in patients with comorbid conditions, a more conservative approach like stenting of the airway can
DOI https://doi.org/ 10.1055/s-0039-3399405 ISSN 0379-038X.
C2019 National Academy of Medical Sciences (India)
License terms

(이 (1) $\Theta \circledast$ 


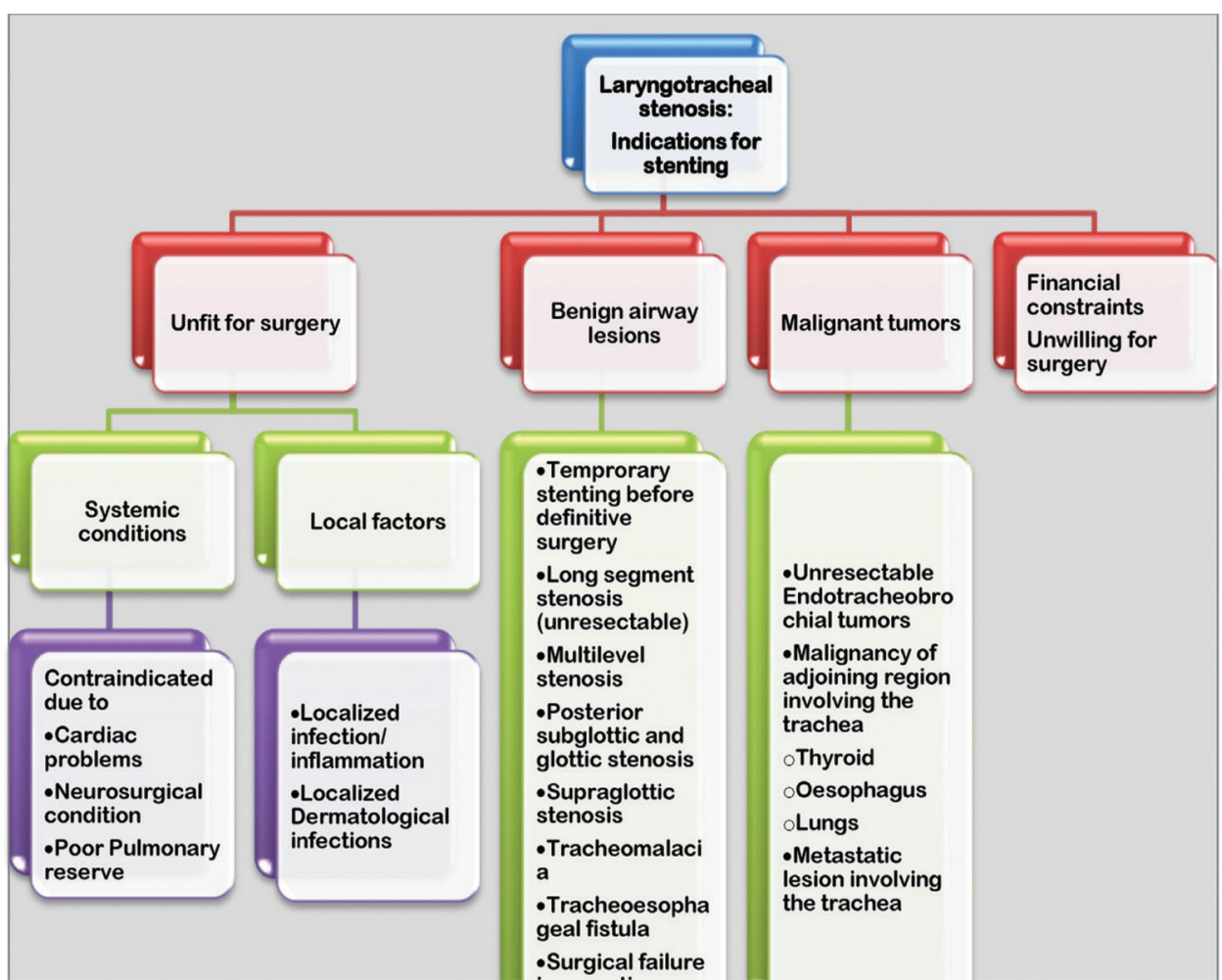

Fig. 1 The adopted flowchart for indications for stenting in laryngotracheal stenosis used in the study.

be successful. Stents need to be used intelligently. ${ }^{3}$ They may be used for temporary stenting for restoration of airway or as a definitive permanent stenting to maintain airway.

\section{Materials and Methods}

Our experience with management of LTS dates back to 2000 when a significant number of tracheotomized patients could not be decannulated due to either subglottic or tracheal stenosis or both. Most of these patients had either been ventilated in the intensive care unit for a prolonged period or had undergone emergency tracheostomy. They were either left with permanent tracheostomy or died due to pulmonary infection leading to septicemia. An initial strategy in treating these patients was confined to excision of granulation tissue on multiple sittings or fitting the tracheostomy tube with a speaking valve. Since 2002, the senior author adopted the technique of tracheoplasty described by "Shiann Yann Lee" in selected cases of tracheal stenosis. The initial success spurred us to use it in more extensive (grade 3 and 4 ) cases of subglottic and/or tracheal stenosis ( - Fig. 1). But, the success was limited due to complications arising out of the " $T$ "-tube.

A retrospective analysis of 51 patients treated from 2004 to 2011 was done. The aim was to identify the indications, complications, and outcome of patients of LTS managed with or without Montgomery T-tube stenting and review the current literature with regard to the role of stenting in LTS. Retrospective chart reviews of 51 patients of LTS who were managed by us during the period 2004 to 2011 were included in the study. After a patient is diagnosed as a case of LTS, further evaluation is done by flexible and rigid endoscopy to assess the movement of vocal cord, type of stenosis, the grade of stenosis, length of stenosis, involvement of the posterior glottis and subglottis, etc. Computed tomography (CT) scan with three-dimensional reconstruction is also performed. A decision is then taken as to the appropriate procedure to be followed. One patient had a posterior glottic stenosis and was managed by laserization of the cicatricial scar without stenting. Two patients who had suprastomal anterior wall collapse were managed by tracheoplasty without stenting. Two patients who had posterior glottic and subglottic stenosis (SGS) had undergone excision of scar tissue followed by stenting with Hood's laryngeal stent. All these five patients were excluded from the study. Eight patients underwent tracheal resection anastomosis, of which one patient had wound dehiscence and required T-tube stenting; hence, seven patients were excluded and one was included in the study. A total of 39 patients who were stented with Montgomery T-tube either for temporary or for definitive treatment were further reviewed and analyzed in this study.

\section{Methodology for Insertion of T-Tube}

We used a very simple technique for insertion of T-tube. Initially, a tracheostomy was performed under local anesthesia to secure the airway. All attempts were made to open the trachea at the site of stenosis or just below it. One to $2 \mathrm{~mL}$ of $4 \%$ lignocaine is instilled in the trachea. The suprastomal trachea and the infrastomal trachea are inspected using a 70-degree nasal endoscope. Stenotic segment was opened by splitting or by tracheoplasty. Granulation within the trachea was removed under vision, using adrenaline-soaked patties over the granulations to reduce bleeding. The vertical limb of the T-tube was smeared with lignocaine gel. The lower part of the vertical limb was first 
introduced into the infrastomal trachea. We generally avoid splitting of normal tracheal rings. Then, the upper limb of the T-tube was held with vascular forceps and introduced suprastomally. Using a 70-degree rigid nasal endoscope through the T-tube, the placement of the T-tube is ascertained, care is taken that the T-tube does not impinge into the glottis (subglottis was avoided if it was disease free). This could be ascertained by visual assessment of the vocal cord mobility and also listening to the patient's voice when he/she phonated. The T-tube could be readjusted, if required. Postoperatively, our patients' required only 1 or 2 days hospitalization for observation. These patients were regularly followed-up, T-tube change is done at 6 monthly intervals, and patient assessed for decannulation when the mucosal regeneration is adequate. We did not close the stoma immediately after decannulation, but observed the patient over a period of 10 days for any narrowing of tracheal lumen after removal of stent. Flap reconstruction of the tracheal stoma was done whenever required. Most of our patients required secondary repair of the tracheal stoma. The data on indications for T-tube stenting, problems/complications of stenting, duration of stenting, and outcome of management were collected, tabulated, and analyzed.

\section{Results}

Of the 39 patients, 32 had developed LTS postendotracheal intubation stenosis and 6 developed LTS posttracheostomy. One patient had thyroid malignancy with infiltration into the trachea causing stenosis and had been managed by T-tube stenting for palliation. Of the 32 patients of endotracheal intubation, 21 had emergency intubation and 11 had elective intubation. The indications for Montgomery T-tube stenting in these 39 patients is shown in - Fig. 1. It is to be noted that two patients were included in both the temporary and permanent category. This is because to start with we used the T-tube stenting as the primary mode of treatment in both: but one patient developed stenosis at both ends of the tube and one patient developed tracheomalacia and required reinsertion of T-tube. Hence, they had to be included in the permanent group also. The most common site of stenosis in the postendotracheal intubation group was in the trachea (48.5\%). All six tracheotomized patients had suprastomal stenosis (100\%). Thirty-eight patients had normal vocal cord mobility at diagnosis. One patient had restricted mobility of the right vocal cord due to scarring and adhesions.

\section{Complications}

The problems that were encountered due to T-tube stenting is shown in - Table 1. Crusting within the tube was a problem in $43.58 \%$ ( - Fig. 2 ), troublesome granulation were seen in the subglottis in $33.33 \%$ ( - Fig. 3), persistent cough in two patients (5.1\%), surgical emphysema in the immediate postoperative period in two patients (5.1\%) ( - Fig. 4),

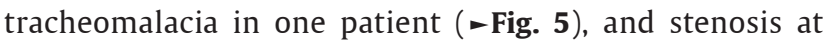
both ends of the T-tube in one patient. One patient did not tolerate the T-tube because of excessive crusting, hence we had to maintain her on permanent tracheostomy tube. Thirty-two patients $(82.05 \%)$ were successfully decannulated and were asymptomatic from 6 months' to 5 years' follow-up. Three patients are still stented with T-tube and one has permanent tracheostomy. Three patients died due to comorbid conditions unrelated to LTS.

\section{Biometric Study of Subglottic and Upper Tracheal Dimensions in Indian Adult Population}

When we analyzed the causes for failure of the "Shiann Yann Lee" tracheoplasty, it was postulated that it could be due to a mismatch in the size and shape of the "T"-tube. Hence, we did a radiological imaging study measuring the dimensions of subglottis and trachea in the Indian adult population. CT scan images of the subglottis and

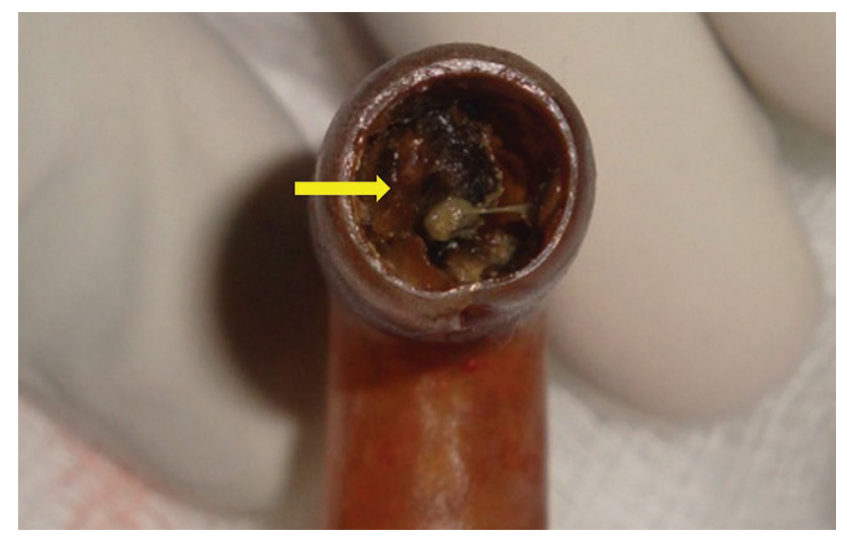

Fig. 2 Crusting within the T-tube.

Table 1 Complications due to T-tube stenting (number of complications out of 51 patients)

\begin{tabular}{|c|c|c|}
\hline $\begin{array}{l}\text { Immediate complications } \\
\text { (within } 24 \text { hours) }\end{array}$ & Intermediate complications (few days to 6 weeks) & $\begin{array}{l}\text { Late complications (few } \\
\text { months) }\end{array}$ \\
\hline $\begin{array}{l}\text { Surgical emphysema (2) } \\
\text { Persistent irritant cough (2) } \\
\text { Respiratory distress } \\
\text { The lower end of the tube } \\
\text { entered one bronchus (1) } \\
\text { Clots and mucus plug (1) }\end{array}$ & $\begin{array}{l}\text { Hoarseness of voice (1) } \\
\text { Respiratory distress } \\
\text { Lower respiratory tract infection (3) } \\
\text { Crusting and mucus plug (17) } \\
\text { Cough with expectoration } \\
\text { Lower respiratory tract infection (3) } \\
\text { Tracheobronchitis ( } 3 \text { ) } \\
\text { Aspiration (4) } \\
\text { Granulations in subglottis and lower end of the tube (14) }\end{array}$ & $\begin{array}{l}\text { Tracheomalacia (1) } \\
\text { Restenosis at both ends of the } \\
\text { tube (1) } \\
\text { Displacement of the tube (1) }\end{array}$ \\
\hline
\end{tabular}

Note: Figure in parenthesis shows number of patients in whom the complications were noted. 


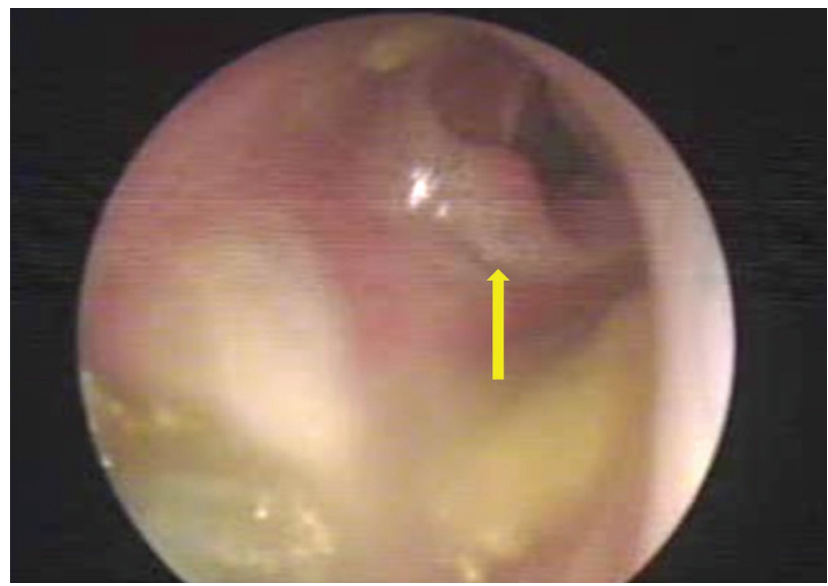

Fig. 3 Granulations in the upper end of T-tube visualized through a 70-degree endoscope.

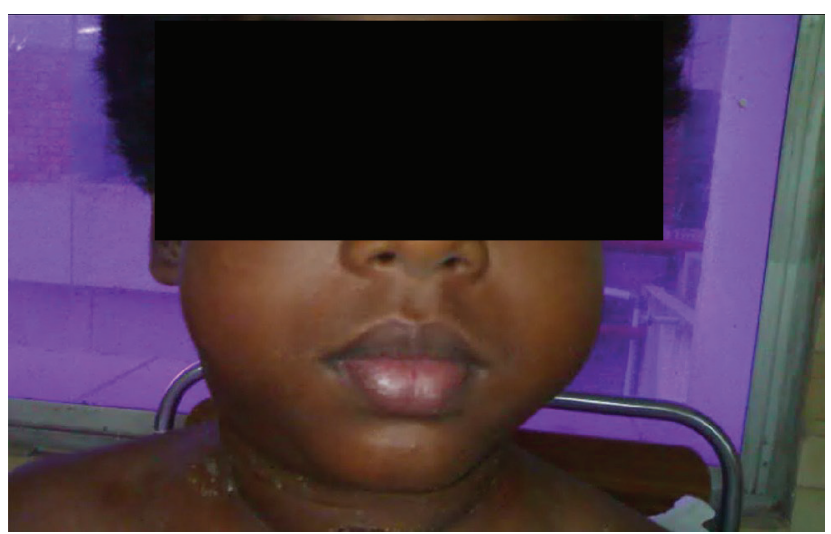

Fig. 4 Surgical emphysema.

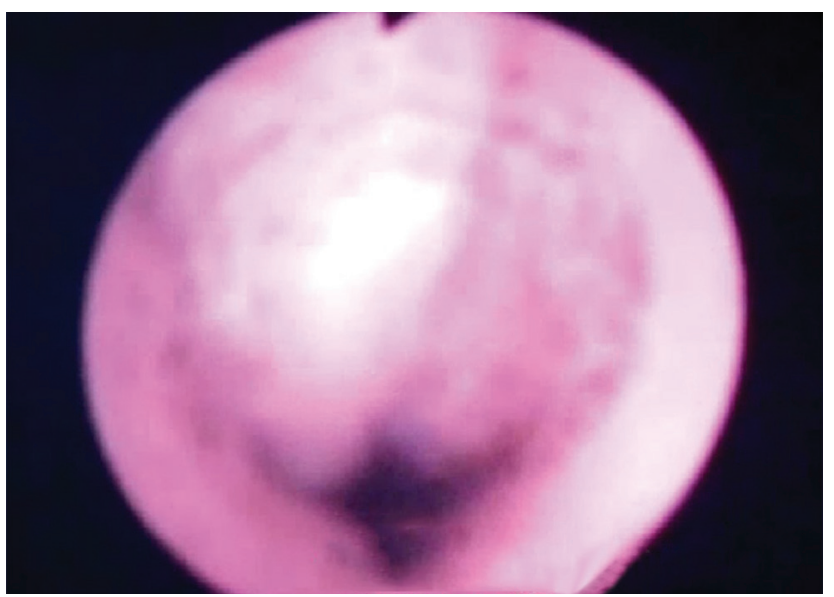

Fig. 5 Tracheomalacia.

trachea of patients undergoing CT scan of neck for other indications were obtained and analyzed by measuring the anteroposterior (AP) and transverse diameter of the trachea at various levels. After comparison with other similar studies (-Table 2 ), it was concluded that the dimensions of the trachea in Indian adult population is lesser when compared with western (Caucasian) population (- Tables 2 and 3$)^{4-10}$

\section{Effect of Thermal Injury in the Subglottis of the Rabbit Animal Model}

To investigate the etiopathogenesis of the nature of injury that occurs in the subglottis and upper trachea following prolonged intubation and in emergency tracheostomy, research was performed by inducing thermal injury in the subglottis and upper tracheal mucosa of New Zealand white rabbits. ${ }^{11}$ This study was conducted at the Central Animal Facility for Toxicology and Developmental Research, Sri Ramachandra University, Chennai, Tamil Nadu, India. Institutional Animal Ethics Committee approval was obtained. The initial studies were performed in postmortem specimens of New Zealand white rabbits weighing 2.0 to $2.5 \mathrm{~kg}$. The cross-sectional diameter of the trachea and subglottis were measured. It was observed that the narrowest part of the rabbit's laryngotracheal airway was the subglottis, measuring on an average $5.8 \mathrm{~mm}$ in AP diameter and $5.4 \mathrm{~mm}$ in transverse diameter. Histopathological changes were noted at various time intervals after the injury and their response to topical mitomycin or corticosteroid application was studied.

\section{Study on Mucosal Healing Response to Topical Application of Mitomycin versus Triamcinolone in Postendotracheal Intubation Injury to the Subglottis and Upper Tracheal Mucosa}

This animal study was focused on the host tissue response to intubation-induced injury resulting in subglottic and upper tracheal stenosis and methods to prevent this complication. Also to assess the role of topically applied mitomycin-C and triamcinolone acetonide in wound healing process following postextubation subglottic and upper tracheal injury. It was a prospective randomized block, single-blinded experimental study. Forty New Zealand white rabbits were block randomized and allocated into four groups based on the type of topical medication that was applied on the mucosa of the subglottis and upper trachea postextubation. Further, these groups were subdivided into three subgroups based on the time of sacrifice $(4,6$, and 12 weeks) to study the histopathological changes that occurred in a temporal sequence at the subglottis. It was observed that the rabbits in the control group and those that received mitomycin-C only had more respiratory distress compared with those treated with triamcinolone acetonide. Statistically significant histopathological changes were observed in all the four groups. Mitomycin-C applied topically did not alter the wound healing process following postextubation injury in the subglottis. Triamcinolone acetonide significantly altered wound healing in the subglottis and prevented occurrence of respiratory distress. Mitomycin-C in a dosage of $0.4 \mathrm{mg} / \mathrm{mL}$, applied topically in four or more sittings did not seem to alter the progress of the healing process and did not prevent postextubation SGS in rabbits as evidenced in this study. Triamcinolone acetonide applied topically has shown to be a better modulator of wound healing in the laryngotracheal airway following intubation-induced injury compared with mitomycin-C. 
Table 2 Internal dimensions of upper trachea by different studies

\begin{tabular}{|c|c|c|c|c|c|}
\hline $\begin{array}{l}\text { Ref } \\
\text { no. }\end{array}$ & Authors & $\begin{array}{l}\text { No. of } \\
\text { subjects }\end{array}$ & Age range & $\begin{array}{l}\text { Tracheal diameter in } \mathrm{mm} \\
\text { (coronal) }\end{array}$ & $\begin{array}{l}\text { Tracheal diameter in mm } \\
\text { (sagittal) }\end{array}$ \\
\hline 4 & $\begin{array}{l}\text { Prasanna Kumar and } \\
\text { Ravikumar }\end{array}$ & $\begin{array}{l}30(\mathrm{M}) \\
18(\mathrm{~F})\end{array}$ & $16-60$ & $\begin{array}{l}11.4-18.2(16.5 \pm 2.38) \\
8.7-15.34(17.34 \pm 3.5)\end{array}$ & $\begin{array}{l}13.6-19.2(12.55 \pm 2.31) \\
8.3-14.33(13.05+ \pm 2.35)\end{array}$ \\
\hline 5 & Katz et al & 50 & Not documented & $13-25$ & Not measured \\
\hline 6 & Jesseph and Merendino & $\begin{array}{l}21(\mathrm{M}) \\
26(\mathrm{~F})\end{array}$ & $13-86$ & $\begin{array}{l}15-27 \\
13-25\end{array}$ & Not measured \\
\hline 7 & Greene & $60(\mathrm{M})$ & 66.4 & $15-26(19.7 \pm 2)$ & $18-32(22.5 \pm 2.4)$ \\
\hline 8 & Breatnach et al & $\begin{array}{l}430(\mathrm{M}) \\
378(\mathrm{~F})\end{array}$ & $20-79$ & $13-25$ & $10-23$ \\
\hline 9 & Brown et al & 40 & Not documented & 18.4 & 20.1 \\
\hline 10 & Kamel et al & $\begin{array}{l}40(\mathrm{M}) \\
20(\mathrm{~F})\end{array}$ & $22-88$ & $\begin{array}{l}20.1-34.5(27.1 \pm 3.4) \\
17.3-27.8(22.9 \pm 2.6)\end{array}$ & $\begin{array}{l}16.8-28.6(22.6 \pm 2.9) \\
12.7-23.8(19.2 \pm 2.6)\end{array}$ \\
\hline
\end{tabular}

Table 3 Adult tracheal dimensions-Sri Ramachandra study (2014)

\begin{tabular}{|l|l|l|l|}
\hline No. of patients (48) & Age in y & $\begin{array}{l}\text { Tracheal diameter in mm } \\
\text { (coronal/transverse) }\end{array}$ & $\begin{array}{l}\text { Tracheal diameter in mm (sagittal/ } \\
\text { anteroposterior) }\end{array}$ \\
\hline $30(\mathrm{M})$ & $18-60$ & $11.4-18.2(16.5 \pm 2.38)$ & $13.6-19.2(12.55 \pm 2.31)$ \\
$18(\mathrm{~F})$ & & $8.7-15.34(17.34 \pm 3.5)$ & $8.3-14.33(13.05 \pm 2.35)$ \\
\hline
\end{tabular}
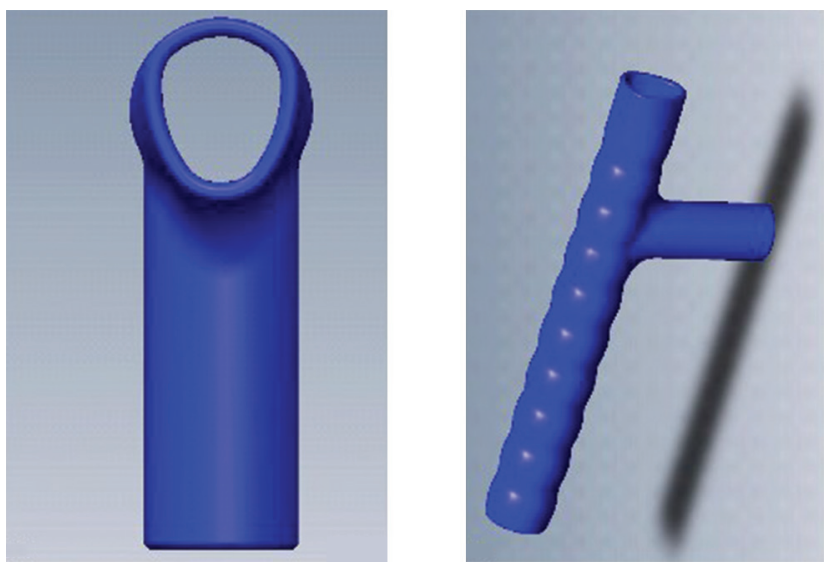

Fig. 6 Design of indigenous T-tube stent.

This research was pursued as a PhD study by the second author under the guidance of the first author. ${ }^{12}$ The research work on rabbits led to the conclusion that the thermal injury of the mucosa of the subglottis and upper trachea increases in severity depending on the depth of mucosal damage and becomes irreversible in prolonged thermal or physical damage. This is permanent and unlikely to be reversed by topical application of anti- inflammatory agents such as mitomycin or corticosteroids, although topical application of triamcinolone acetonide had a beneficial effect in the early period after extubation. ${ }^{13}$

\section{Design and Development of Indigenous T-Tube Stent for Rabbit Model}

Based on the observations in the animal study and the limitations and complications noted when the Montgomery T-tube was used in patients with LTS, we started probing the alternate method of treatment using silastic stents in subglottic and upper tracheal stenosis. The time-honored Montgomery $\mathrm{T}_{\text {-tube }}{ }^{14}$ made of silastic that we were using was excellent except that the shape was found to be mismatched to that of the subglottis leading to formation of inflammatory granulation tissue at the upper end in the subglottis. Several other stents were developed by other researchers which did not fulfill all the requirements of an ideal stent. ${ }^{15-25}$

Therefore, we decided to develop an indigenous T-tube made of silastic and coated with titanium dioxide on the outside. The raw material was chosen carefully and the shape of the tube was custom-made to suit the inner dimensions of the subglottis and upper trachea (-Fig. 6). The external surface was of a wavy pattern to reduce the chances of mucus accumulation and the angle of the horizontal limb was made acute to match the angulation of the trachea ( - Fig. 7). This tube was tried out in the rabbit model after endotracheal tube-induced mucosal damage leading to stenosis of the subglottis and upper trachea. It proved to be effective and the statistical analysis of the results proved its benefits in reducing the incidence of stenosis by applying topical triamcinolone in this animal model. After adequate follow-up, it was concluded that the newly developed indigenous T-tube was more effective in subglottic and upper tracheal stenosis in rabbits that were used in this study. ${ }^{13}$ This stent has been patented. The patent was filed on August 23, 2013 and published on February 27, 2015; Official Journal of the Patent Office, Issue no.09/2015, p. 26968; Appl. no.3728/CHE/2013 A.

We plan to continue this study by developing a stent for use in human patients affected by subglottic and upper tracheal stenosis. It is expected that this would be a cheaper and more effective T-tube than the Montgomery T-tube that is being used nowadays. 


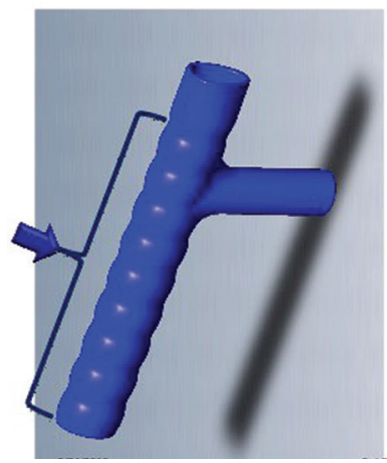

- The outer contour is smooth but wavy

- Dynamic and flexible

- Spring effect along with the direction of flow

- Does not compromise on rigidity

- Stent more stable within the tracheal lumen

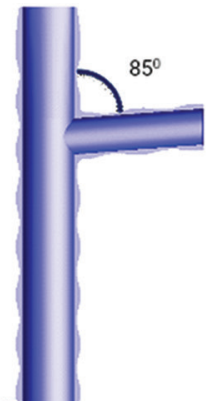

( The horizontal limb is angulated at $85^{\circ}$ to the vertical

$\square$ Aids visualization and suctioning

Fig. 7 Unique characteristics of the new stent.

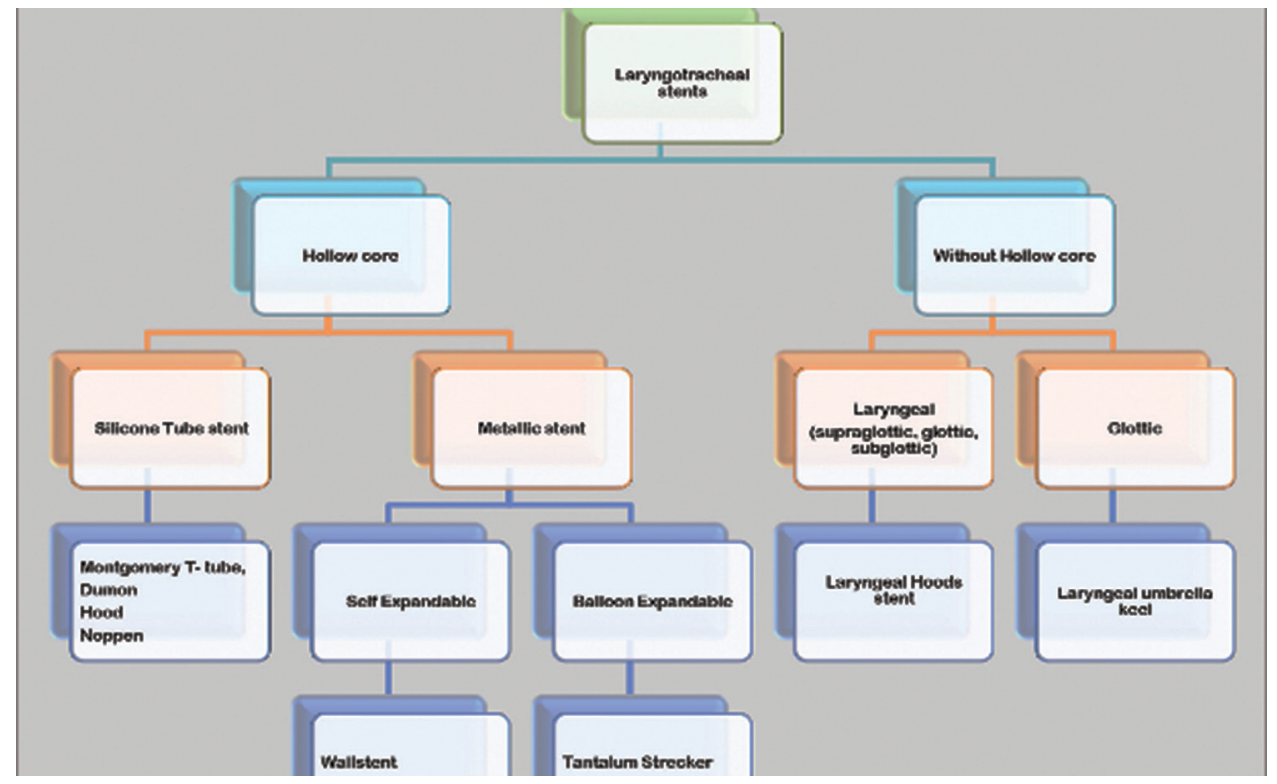

Fig. 8 Types of laryngotracheal stents.

\section{Discussion}

Laryngotracheal injuries that occur due to endotracheal intubation or due to tracheostomy may result in temporary reversible laceration and edema or leave behind a chronic scar resulting in LTS. Cooper and Grillo in 1969 analyzed and listed the types of injuries in postmortem specimens of patients who were ventilated using a cuffed endotracheal tube or cuffed tracheostomy tube. ${ }^{26}$

There was an alarming increase in the incidence of LTS especially in children following endotracheal intubation which Othersen called it "a new epidemic." ${ }^{27}$ The reported incidence of laryngotracheal injuries following endotracheal intubation varied from $62^{8}$ to $94 \%$ for temporary laryngeal injuries ${ }^{28}$ and 10 to $20 \%$ of these result in permanent laryngeal sequelae such as LTS. The incidence of laryngotracheal injuries reportedly had reduced after the use of "high-volume low-pressure cuffed endotracheal tubes." Incidence of SGS in the 1970s and 1980s was around 0.9 to $8.3 \%$ in neonates. Schweiger et al have reported a high incidence $(11.38 \%)$ of SGS in children who were endotracheally intubated..$^{29}$
Several factors influence the severity of injury and the progress to formation of SGS. The most critical risk factor for postintubation SGS in neonates and children is the size of the tube. .0,31 $^{30}$ To have documented evidence of normative data on the dimension of the endoluminal dimension of the subglottis and upper trachea in Indian population, a CT study was undertaken by us which showed that compared with the western literature the dimension of the subglottis and upper trachea in adult Indian population was less as shown in - Table 3 .

The management of LTS is varied and needs to be catered to each patient's needs, depending on the type and severity of stenosis, and also the existing comorbidity. We have identified the indication for Montgomery T-tube stenting which has been listed in - Fig. 1. The complications that occurred with the use of T-tube that has been listed in - Table 1 , and the types of available stents for use in LTS that has been listed in $\boldsymbol{- F i g . ~ 8 . ~}{ }^{32-34}$

Research is on to develop an ideal stent for managing LTS. No ideal stent is available yet. ${ }^{16-18}$ At present, the Montgomery T- tube is widely used all over the world for treating LTS. ${ }^{35-38}$ Review of literature has shown that silastic is an ideal material that is relatively bioinert and hydrophobic; hence, less of crust 
formation. ${ }^{39,40}$ On similar lines, we had undertaken a DSIR project and successfully developed an indigenous stent that can be custom-made to the individual and also reduce the potential complications. This stent used in the rabbit model has been patented and a similar stent is being developed for human trials. Drug-eluting stents are being proposed and are on trial to reduce the recurrence of stenosis. As research in this field is minimal, we have described an animal model to produce airway injury to carry out further research in postintubation LTS. ${ }^{11}$

Hirshoren and Eliashar have described the various factors, chemical mediators, and the drugs that modulate wound healing. The most common drugs that are widely used are: corticosteroids and mitomycin-C. The role of both these drugs have been evaluated and debated with no concrete evidence that they influence and modulate wound healing in postintubation LTS. ${ }^{41}$ To this end, we have studied the effect of two drugs mitomycin-C and triamcinolone as topical application in postintubation injury in New Zealand white rabbits and have found that triamcinolone showed statistically significant reduction in the occurrence and prevention of stenosis in the early stages. ${ }^{12,13}$

\section{Conclusion}

Regular clinical audits during the course of managing patients with LTS resulted in research which identified that the internal dimensions of the subglottis and upper trachea in Indian population is less than that reported in western literature. The management of LTS has to be individualized to cater to the need of the patient. An ideal stent and $\operatorname{drug}(\mathrm{s})$ for the management of LTS has not been developed. This opens up a requirement of Fellowship course in India. Hence, to our mind, there is a lot of scope for airway research in India.

\section{Note}

The author was selected for Col. Sangham Lal Memorial Oration for the year 2018-2019.

\section{Conflict of Interest}

None declared.

\section{References}

1 Grillo HC, Donahue DM, Mathisen DJ, Wain JC, Wright CD. Postintubation tracheal stenosis. Treatment and results. J Thorac Cardiovasc Surg 1995;109(3):486-492

2 Gómez-Caro A, Morcillo A, Wins R, Molins L, Galan G, Tarrazona $\mathrm{V}$. Surgical management of benign tracheal stenosis. Multimed Man Cardiothorac Surg 2011;2011(1111):004945

3 Grillo HC. Stents and sense. Ann Thorac Surg 2000;70(4):1142

4 Prasanna Kumar S, Ravikumar A. Biometric study of the internal dimensions of subglottis and upper trachea in adult Indian population. Indian J Otolaryngol Head Neck Surg 2014;66(Suppl 1):261-266

5 Katz I, Levine M, Herman P. Tracheobronchiomegaly. The Mounier-Kuhn syndrome. Am J Roentgenol Radium Ther Nucl Med 1962;88:1084-1094

6 Jesseph JE, Merendino KA. The dimensional interrelationships of the major components of the human tracheobronchial tree. Surg Gynecol Obstet 1957;105(2):210-214
7 Greene R. "Saber-sheath" trachea: relation to chronic obstructive pulmonary disease. Am J Roentgenol 1978;130(3):441-445

8 Breatnach E, Abbott GC, Fraser RG. Dimensions of the normal human trachea. Am J Roentgenol 1984;142(5):903-906

9 Brown BM, Oshita AK, Castellino RA. CT assessment of the adult extrathoracic trachea. J Comput Assist Tomogr 1983;7(3):415-418

10 Kamel KS, Lau G, Stringer MD. In vivo and in vitro morphometry of the human trachea. Clin Anat 2009;22(5):571-579

11 Kumar SP, Ravikumar A, Thanka J. An animal model for laryngotracheal injuries: an experimental study. Laryngoscope 2015;125(1):E23-E27

12 Kumar SP, Subglottic and upper tracheal mucosal response to intubation induced injury and medication - An animal study [thesis]. Chennai: Sri Ramachandra University; 2007

13 Prasanna Kumar S, Ravikumar A, Thanka J. Role of topical medication in prevention of post extubation subglottic stenosis. Indian J Otolaryngol Head Neck Surg 2017;69(3):401-408

14 Montgomery WW. T-tube tracheal stent. Arch Otolaryngol 1965;82:320-321

15 Dumon JF. A dedicated tracheobronchial stent. Chest 1990;97 (2):328-332

16 Lee P, Kupeli E, Mehta AC. Airway stents. Clin Chest Med 2010;31(1):141-150

17 Monnier P. A new stent for the management of adult and pediatric laryngotracheal stenosis. Laryngoscope 2003;113 (8):1418-1422

$18 \mathrm{Zhu} \mathrm{GH}$, Ng AH, Venkatraman SS, et al. A novel bioabsorbable drug-eluting tracheal stent. Laryngoscope 2011;121(10):2234-2239

19 Robey TC, Välimaa T, Murphy HS, Tôrmâlâ P, Mooney DJ, Weatherly RA. Use of internal bioabsorbable PLGA "finger-type" stents in a rabbit tracheal reconstruction model. Arch Otolaryngol Head Neck Surg 2000;126(8):985-991

20 Pereszlenyi A, Igaz M, Majer I, Harustiak S. Role of endotracheal stenting in tracheal reconstruction surgery-retrospective analysis. Eur J Cardiothorac Surg 2004;25(6):1059-1064

21 Carretta A, Casiraghi M, Melloni G, et al. Montgomery T-tube placement in the treatment of benign tracheal lesions. Eur J Cardiothorac Surg 2009;36(2):352-356

22 Pinedo-Onofre JA, Téllez-Becerra JL, Patiño-Gallegos H, Miranda-Franco A, Lugo-Alvarez G. Subglottic stenosis above tracheal stoma: technique for Montgomery T-tube insertion. Ann Thorac Surg 2010;89(6):2044-2046

23 Jacobsen N, Pitkin L, Gleeson M. An effortless way of inserting a Montgomery T-tube stent in a closed neck. J Laryngol Otol 2006;120(9):774-775

24 Davis N, Madden BP, Sheth A, Crerar-Gilbert AJ. Airway management of patients with tracheobronchial stents. $\mathrm{Br} J$ Anaesth 2006;96(1):132-135

25 Phillips PS, Kubba H, Hartley BEJ, Albert DM. The use of the Montgomery T-tube in difficult paediatric airways. Int J Pediatr Otorhinolaryngol 2006;70(1):39-44

26 Cooper JD, Grillo HC. The evolution of tracheal injury due to ventilatory assistance through cuffed tubes: a pathologic study. Ann Surg 1969;169(3):334-348

27 Othersen HB, Jr. Subglottic stenosis: a new epidemic in children. Contemp Surg 1978;13:9

28 Rangachari V, Sundararajan I, Sumathi V, Krishna KK. Laryngeal sequelae following prolonged intubation: a prospective study. Indian J Crit Care Med 2006;10(3):171-175

29 Schweiger C, Marostica PJ, Smith MM, Manica D, Carvalho PR, Kuhl G. Incidence of post-intubation subglottic stenosis in children: prospective study. J Laryngol Otol 2013;127(4):399-403

30 Pashley NR. Risk factors and the prediction of outcome in acquired subglottic stenosis in children. Int J Pediatr Otorhinolaryngol 1982;4(1):1-6 
31 Contencin P, Narcy P; Study Group for Neonatology and Pediatric Emergencies in the Parisian Area. Size of endotracheal tube and neonatal acquired subglottic stenosis. Arch Otolaryngol Head Neck Surg 1993;119(8):815-819

32 Srirompotong S, Yimtae K. Dislodge of T-tube into the bronchus, an unusual complication of the Montgomery T-tube: a case report. J Med Assoc Thai 2001;84(12):1772-1774

33 Shinkwin CA, Murty GE, Gibbin KP, Bradley PJ. Inhalation of a Montgomery safe T-tube plug. J Laryngol Otol 1992;106(11):1004-1005

34 Prasanna Kumar S, Ravikumar A, Senthil K, Somu L, Nazrin MI. Role of Montgomery T-tube stent for laryngotracheal stenosis. Auris Nasus Larynx 2014;41(2):195-200

35 Saghebi SR, Zangi M, Tajali T, Farzanegan R, Farsad SM, Abbasidezfouli $A$. The role of T-tubes in the management of airway stenosis. Eur J Cardiothorac Surg 2013;43(5):934-939

36 Lund ME, Force S. Airway stenting for patients with benign airway disease and the Food and Drug Administration advisory: a call for restraint. Chest 2007;132(4):1107-1108
37 Cooper JD, Pearson FG, Patterson GA, et al. Use of silicone stents in the management of airway problems. Ann Thorac Surg 1989;47(3):371-378

38 Liu HC, Lee KS, Huang CJ, Cheng CR, Hsu WH, Huang MH. Silicone T-tube for complex laryngotracheal problems. Eur J Cardiothorac Surg 2002;21(2):326-330

39 Martinez-Ballarin JI, Diaz-Jimenez JP, Castro MJ. Moya JA. Silicone stents in the management of benign tracheobronchial stenoses. Tolerance and early results in 63 patients. Chest 1996;109(3):626-629

40 Puma F, Ragusa M, Avenia N, et al. The role of silicone stents in the treatment of cicatricial tracheal stenoses. J Thorac Cardiovasc Surg 2000;120(6):1064-1069

41 Hirshoren N, Eliashar R. Wound-healing modulation in upper airway stenosis-Myths and facts. Head Neck 2009;31 (1):111-126 